\title{
LIFE CYCLE ASSESSMENT OF COMPOSITE FOOTBRIDGES IN A POSTGRADUATE OPTIMIZATION COURSE THROUGH A CASE STUDY
}

\author{
D. Martínez-Muñoz' ${ }^{1}$ J.V. Martí1 ${ }^{1}$ V. Yepes ${ }^{1}$, V.J. López-Desfilis ${ }^{2}$ \\ ${ }^{1}$ ICITECH. Dept. Ingeniería de la Construcción y Proyectos de Ingeniería Civil. Universitat \\ Politècnica de València (SPAIN) \\ ${ }^{2}$ Dpto. de Mecánica de los Medios Continuos y Teoría de Estructuras. Universitat Politècnica \\ de València (SPAIN)
}

\begin{abstract}
This paper describes how, through a case study, the life cycle assessment methodology is introduced in a postgraduate course. This case study is carried out within the framework of the predictive models of optimization of concrete structures subject of the master's degree in concrete engineering. This course introduces students to methods like the optimization of structures through the application of algorithms, and other concepts like multi-criteria decision making, design of experiments, and methods of prediction and regression. In this case study, the life cycle assessment of a simply supported $28 \mathrm{~m}$ span length mixed footbridge is carried out. The section is composed of a metal beam that supports a concrete slab, both elements are joined by shape connectors. The geometric definition is carried out applying an optimization algorithm. To carry out the analysis, the students will use the Ecoinvent database, and must make different hypothesis about the scenarios used for the procedures. As a result of applying logic to solve a case study using specific software and deducing the impact of a construction; this activity will help students to acquire different transversal competencies, such as ethical and environmental responsibility, knowledge of contemporary problems, critical thinking, and specific instrumental use, all of them framed within the institutional project of the Universitat Politècnica de València. This paper will introduce future studies related to the life cycle assessment of footbridges, not only from an energetic and environmental point of view but also an economic and social one.
\end{abstract}

Keywords: engineering training, postgraduate course, applied research, sustainability, footbridge, lifecycle, environmental impact.

\section{INTRODUCTION}

\subsection{Postgraduate studies in the engineering field}

The education in a European context needs the technological disciples to improve its economic development. Postgraduate courses allow students to complement their general education with specific scientific knowledge to specialise in a particular field. The master (MSc) level is recognized in most of the European countries. The Polytechnic University of Valencia has a great number of these postgraduate courses. The Master in Concrete Engineering began in October 2007, from the doctoral programme $(\mathrm{PhD})$ of the Department of Construction Engineering and Civil Engineering Projects and it has the EUR-ACE label that certifies the quality of the teaching of this degree. Only a few degrees in engineering have this recognition. The objective of this communication is to present one of the most relevant subjects of this master, "Predictive models and structural concrete optimization". Its contents are very closely related with the research work, and it is a good example of the connection between the work of teachers and researchers [1-6].

\subsection{Background}

Over the last years, the concerns of the society about the environment have been increasing. Because of this, terms like "sustainable development" have appeared more frequently. This concept was introduced by the Brundtland Commission, that defines it that as the "development that meets the needs of the present without compromising the ability of future generations to meet their own needs" [7]. Since then, countries and governments have been doing a lot of effort, investing to improve the processes to reduce the emissions to the environment, giving more importance to take care of the 
environment. This involves a change on the direction of the thinking of society. The assessment of constructions is not only valued on terms of economic cost. Other factors have gained importance, like the social and environmental impacts, and the concept of a good construction is the one that considers those factors in addition to the cost. This leads to integrate different weights for every factor to perform a decision-making process.

The construction industry is one of the most important sectors that contributes to climate change [8], [9], and it is essential to achieve sustainability. Bridges are a characteristic structure of the constructions sector that have been studied specially [10]. Therefore, some authors reviewed the decision making methods [11] and the multi-criteria optimization [12]. Sustainable construction is the one that allows rating all the factors to reach the best solution. This opens a new field, the optimization with different criteria along with the cost, that have been the first indicator studied [13]. García-Segura et al. [14] studied the multiobjective optimization of post-tensioned concrete box-girder road bridges considering $\mathrm{CO} 2$ emissions and safety. Martí et al. [15] used a hybrid simulated annealing (SA) to obtain the optimum embodied energy solution for U-beam road bridges. Penadés-Plà et al. [16] studied accelerated optimization methods for low-embodied energy concrete box-girder bridge design. Other authors have been looking for advanced optimization techniques to study their application in civil engineering [17]. Our research group has employed many algorithms to optimize different structures taking into account different social, environmental and cost criteria [18-24].

Other authors have focused their study on the environmental impact analysis using the LCA method [25]. Pons et al. [26] and Zastrow et al. [27] compared different earth-retaining walls from the environmental point of view. Penadés-Plà et al. [28] did it with post-tensioned concrete box-girder bridges. In this paper, we have focused our study on comparing the environmental impact of the construction of a steel-concrete composite pedestrian bridge, with an LCA method in the five countries with the highest steel production ratio of Europe: Germany, Italy, France, Spain and Poland. This work raises the awareness of the students to know the importance of the steel manufacturing processes, and how the proportion of recycled steel used for its construction affects its environmental impact, fostering their abilities of critical thinking and knowledge about contemporary problems.

\section{LCA METHOD}

The LCA method makes it possible to assess the impact of a product during its complete life cycle by assigning an impact to each of the sub-processes that constitute the stages of the life cycle of a structure. LCA is currently one of the most accepted methods for the evaluation of the impact of a process or activity, allowing this evaluation the possibility to study how to reduce the impact of the activities required for a process. Therefore, LCA allows the possibility to make a quantitative assessment of the sustainability of a construction, as well as to reduce its total impact. To be able to correctly define the methodology, ISO 14040:2006 proposes some diagrams of the processes considered at each stage of the life cycle of a bridge.

\subsection{Goal and functional unit}

The objective of the assessment of the life cycle of a structure is to obtain a quantitative value of the environmental impact associated with our structure to ensure its sustainability. To perform this comparison, we must define the boundary conditions and the functional unit [29]. Pang et al. [30] concluded that there are three reasons to carry out the analysis of the life cycle in bridges: comparison of different alternatives, comparison of different bridge component alternatives, and comparison of new material with conventional material component. To compare between different bridges, we must take into account factors such as: the life-span, the dimensions of the deck or the loads that the structure receives, because changes in these parameters cause variations in the needs of the resistance of the sections, and therefore, the geometrical distribution, or even the type of material. In case that the bridges are in different locations, we must take into account geotechnical or seismic conditions in the area among other factors. All these factors will affect the design of the bridge.

Once the dimensioning and testing of the bridge is done, we must define the unit of comparison. The mostly used units for bridges are: one $m$ length of the bridge and the square meter of the bridge. If the first one is chosen as a functional unit, to compare different bridges they should have the same width of the deck. In this work square meters have been used as a functional unit.

In addition, must take into account the geographical location of our system, because it will define its inputs and outputs. For the analysis of the life cycle of a structure, we must consider the conditions of 
each one of the phases of the life of the structure. To do this, we need to know the details of the provider of the information database. The most reliable database that considers processes that are conducted in the construction sector is Ecoinvent, by constantly updating the database.

\subsubsection{Ecoinvent database processes}

The Ecoinvent database has processes whose impacts depend on the location of the site. In its first versions, the data was obtained in Switzerland $(\mathrm{CH})$, including some processes that were valid for Europe (RER). New information on other locations in Canada (CA-QC), Germany (DE), Rest of World (RoW), and Global (GLO) was added in later versions.

In addition, when carrying out a LCA, it must be taken into account that processes can vary depending on the temporary or technical field. For example, it is not the same to manufacture $1 \mathrm{~kg}$ of steel in Germany than in Spain, since the distances between plants and quarries, and transport or the amount of steel recycled in the manufacturing process is different. Thus, the data obtained from the database for a specific geographical area should be associated with the uncertainty of these processes.

\subsubsection{Uncertainty}

The uncertainty should be considered in two stages. On the one hand, there is an uncertainty associated with the nature of the process [31]. In addition there is another uncertainty depending on other indicators, which is resolved with Pedigree's Matrix [32]. These indicators, which are evaluated in the matrix are: Reliability, Completeness, Temporal correlation, Geographical correlation, and further technological correlation.

All the processes that must be considered for the analysis of the life cycle of a structure can be grouped in four phases: Manufacturing, Construction, Use and Maintenance, and End of Life. The allocation of each one of the processes in the phases of the life cycle is based on the order in which they will appear during the life of the structure. In this paper we focus on the study of a composite footbridge, but this methodology can be used both for other gateways of different materials and for other types of bridges.

\subsubsection{Software and parameters}

The software that has been used for the life cycle assessment of the footbridge has been the openLCA of the Greendelta company program. This software allows you to create processes that form each of the phases of the life of the structure, and to introduce other obtained directly from a database as Ecoinvent. That software lets you obtain results of the environmental impact that have the activity or process that we are modeling by means of an impact assessment method.

\subsection{Case Study: Simply supported composite footbridge}

Footbridges are structures that allow the passage of people from one point to another to save an obstacle, this type of structures can be manufactured with different materials. In this case, since the structure only has two supports, a composite solution is optimal to resist the efforts, mostly the positive bending that it will be subjected to, taking advantage of the good behavior of steel to resist tractions and concrete to resist compressions.

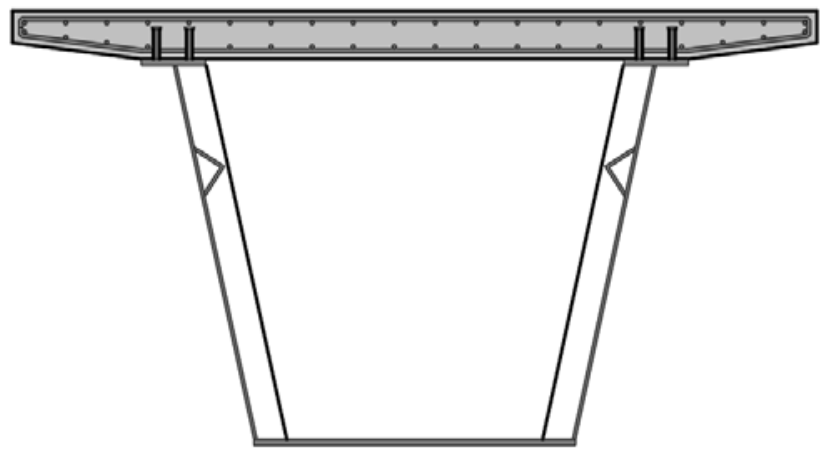

Figure 1. Footbridge's transversal section. 
The footbridge which has been modeled consists of a metal section that supports a slab of concrete (Fig. 1), this section has previously been optimized using optimization algorithms to minimize the cost. The width of the runway is 2.5 meters and the dimensions of the rest of the elements vary depending on the length. In composite footbridges, the most important material regarding to the total cost is the steel, so small variations in the same manufacturing process can vary the impact of our footbridge.

Currently there are two processes for the majority of the steel manufacturing: Basic Oygen Furncace (BOF) and Electric Arc Furnace (EAF). In the BOF process, iron is combined with less than $30 \%$ of steel scrap (recycled steel), and for the EAF around $90-100 \%$. These two processes have different environmental impacts, and the total value of the percentage of recycled steel used in the manufacture phase is directly related to these processes.

To carry out the full analysis of the life cycle, we need to know the amount of materials used for the construction of the footbridge and its construction procedure, in Table 1 we can find the values of quantities of material for each of the considered lights.

Table 1. Value of the material quantities and characteristics.

\begin{tabular}{cccccc}
\hline Length $(\mathbf{m})$ & $\begin{array}{c}\text { Structural } \\
\text { Steel }(\mathbf{k g})\end{array}$ & $\begin{array}{c}\text { Shear Connector } \\
\text { Steel } \mathbf{( k g )}\end{array}$ & $\begin{array}{c}\text { Concrete } \\
(\mathbf{m} 3)\end{array}$ & $\begin{array}{c}\text { Strength } \\
(\mathbf{M P a})\end{array}$ & $\begin{array}{c}\text { Reinforcement } \\
\text { Steel } \mathbf{( k g )}\end{array}$ \\
\hline 28.00 & 8858.96 & 62.50 & 9.81 & 25 & 1248.98 \\
\hline
\end{tabular}

The objective of this study is to conduct a full life cycle analysis to study the variation of the impact of a structure based on the manufacturing processes that are used in different countries. To do this, we have compared the values of the five largest producers of steel in Europe [33]: Germany, Italy, France, Spain and Poland. In Table 2 we can see the total steel production and the percentage of each BOF or EAF process that has been used in each one.

Table 2. Value of steel production of each country.

\begin{tabular}{lccccc}
\hline Country & $\begin{array}{c}\text { Thousand } \\
\text { Tonnes }\end{array}$ & $\begin{array}{c}\text { \%total } \\
\text { production }\end{array}$ & \%BOF & \%EAF & \%Recycled \\
\hline Germany & 42080 & $25.97 \%$ & $70.10 \%$ & $29.90 \%$ & $43.22 \%$ \\
Italy & 23373 & $14.43 \%$ & $24.30 \%$ & $75.70 \%$ & $80.32 \%$ \\
France & 14413 & $8.90 \%$ & $66.10 \%$ & $33.90 \%$ & $46.46 \%$ \\
Spain & 13616 & $8.40 \%$ & $33.40 \%$ & $66.60 \%$ & $72.95 \%$ \\
Poland & 9001 & $5.56 \%$ & $56.8 \%$ & $43.2 \%$ & $53.99 \%$ \\
\hline
\end{tabular}

Once we have the input data for the analysis of the life cycle of the structure, we will sort the processes to the corresponding phases of the life cycle of the pedestrian footbridge. The insertion of these processes into the life cycle analysis software is carried out. The values of the parameters used are shown in Table 3.

\subsubsection{Manufacturing}

At this stage, you consider the manufacturing process of all materials that will form the composite footbridge. The Ecoinvent database has processes that define these materials, such as the concrete or the reinforcement steel, considering the activities required for each of these products. Sometimes, to make a detailed study of these processes, it can be an advantage to create your own specific processes through the use of disaggregated basic processes.

In the case of the concrete, the process defined in the Ecoinvent database has been used, since the variation of the characteristics of this material do not impose a significant change in the final result. However, for the steel, we need to model the manufacture of steel in each of the countries. The Ecoinvent database includes these processes, considering a recycled steel percentage of around $19 \%$ for the BOF and $100 \%$ for the EAF.

As you can see in Table 1, we have three types of steel: structural steel, shear connector steel and steel reinforcement. Each of the processes has been modelled by adding hot rolling processes. We 
also need a formwork for the concrete of the slab. A galvanized steel sheet is used for this, it has been modeled like the rest of steels, but adding the process of the zinc coating of the plate.

Moreover, in this phase, the processes of welding of the plates that make up the metal beam that will support the slab and connectors are considered as well. The deck is assembled in lengths of less than $12 \mathrm{~m}$ to be transported to the place of construction.

The distances considered from the places of manufacture until the construction zone have been $25 \mathrm{~km}$ for the concrete plant and $150 \mathrm{~km}$ for the steel-making workshop.

\subsubsection{Construction}

This phase encompasses all the actions that are conducted to build the structure, making it available for its service phase. Activities that have been taken into account in this phase have been, on the one hand, welding of girder sections previously welded in the manufacturing phase, pouring and vibration of the concrete, the execution of the epoxy bearing layer and the elevation of the complete deck, previously built on the ground, to the end position by means of the use of a crane. The placement of the bearing course is done manually, because of this it has taken into account at this stage only the manufacture of materials.

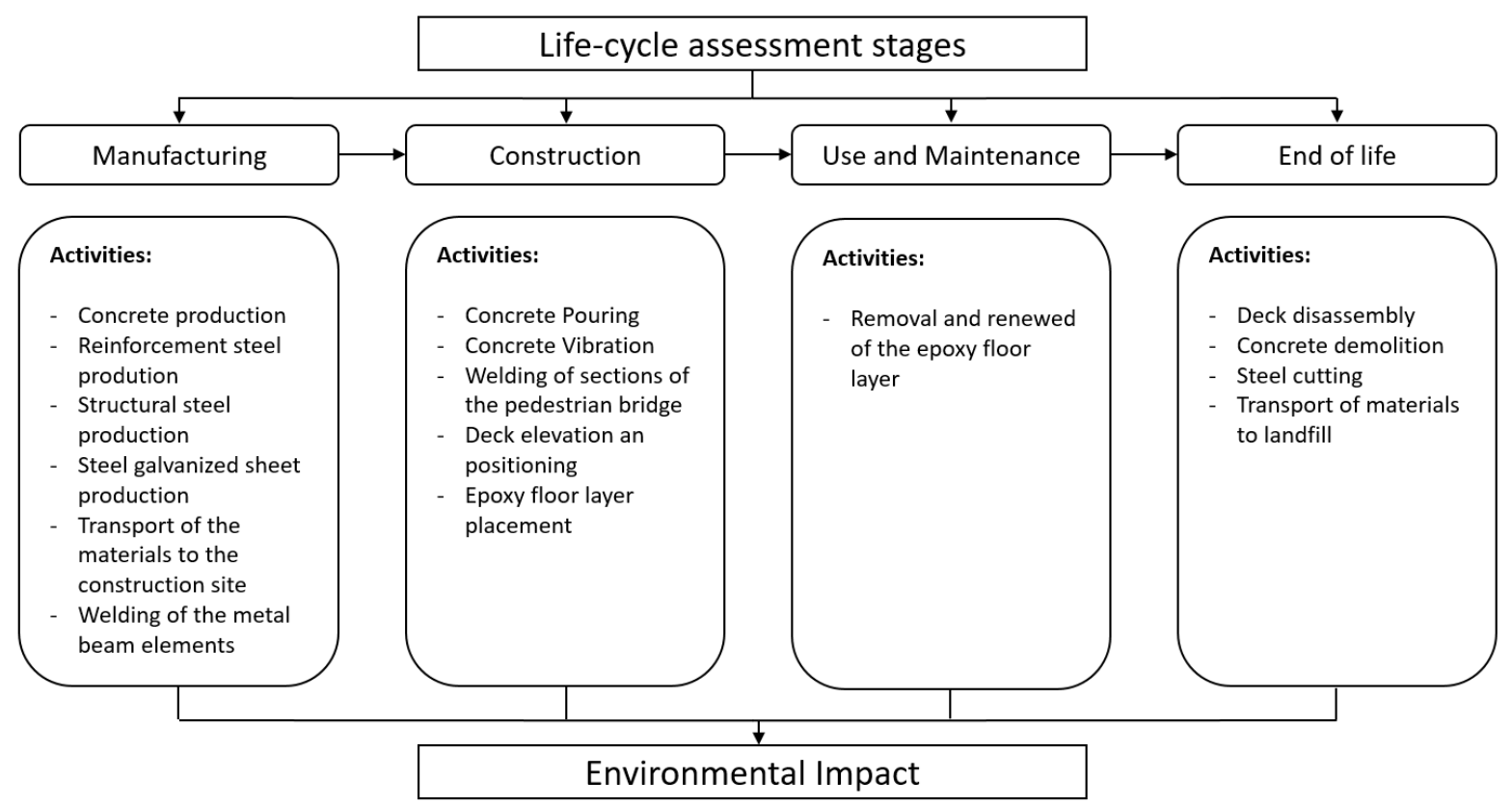

Figure 2. Life cycle stages and activities considered.

\subsubsection{Use and maintenance}

For the operation and maintenance phase, the hypothesis is that the complete floor layer has to be renewed, which is made by including again the manufacture of materials that make up the layer: mortar of epoxy resin, acrylic mortar and acrylic paint. $\mathrm{CO}_{2}$ fixation processes have not taken into account since the exposed surface of the concrete is very small and the effect of this process does not change the result.

\subsubsection{End of life}

This is the last phase of the life cycle, and the processes which have been considered are the dismantling of the deck and the transport of the materials to landfill. To model this phase, the processes that have been taken into account are the concrete demolition, removal of the deck by means of a crane to perform the disassembly on the ground, the cutting of steel and transportation to the landfill. The distance considered for the transportation to the landfill was $30 \mathrm{~km}$.

The processes related to the treatment of the materials in the landfill have not been considered in this phase because the recycling of steel is already considered in the manufacturing process of each of the types of steel that make up the structure. 
Table 3. Value of the parameters used in the LCA model.

\begin{tabular}{llr}
\hline Name & Unit & Value \\
\hline Concrete_25 & $\mathrm{m} 3 / \mathrm{m} 2$ & 0.140 \\
Dist_Concrete & $\mathrm{km}$ & 25.000 \\
Dist_Landfill & $\mathrm{km}$ & 30.000 \\
Dist_Steel & $\mathrm{km}$ & 150.000 \\
Filler_Acrylic & $\mathrm{kg} / \mathrm{m} 2$ & 1.200 \\
Paint_Acrylic & $\mathrm{kg} / \mathrm{m} 2$ & 0.300 \\
Resin_Epoxy & $\mathrm{kg} / \mathrm{m} 2$ & 0.800 \\
Steel_Connector & $\mathrm{kg} / \mathrm{m} 2$ & 0.893 \\
Steel_Galvanized & $\mathrm{kg} / \mathrm{m} 2$ & 7.850 \\
Steel_Reinforcement & $\mathrm{kg} / \mathrm{m} 2$ & 17.843 \\
Steel_Structural & $\mathrm{kg} / \mathrm{m} 2$ & 126.557 \\
Surface_Galvanized & $\mathrm{m} 2 / \mathrm{m} 2$ & 1.000 \\
Time_Crane & $\mathrm{h} / \mathrm{m} 2$ & 0.086 \\
Time_Demolition & $\mathrm{h} / \mathrm{m} 2$ & 0.047 \\
Time_Edge & $\mathrm{h} / \mathrm{m} 2$ & 0.143 \\
Time_Pouring & $\mathrm{min} / \mathrm{m} 2$ & 0.529 \\
Time_Vibrator & $\mathrm{min} / \mathrm{m} 2$ & 0.529 \\
Welding_Long & $\mathrm{m} / \mathrm{m} 2$ & 0.400 \\
Welding_SC & $\mathrm{m} / \mathrm{m} 2$ & 0.091 \\
Welding_Trans & $\mathrm{m} / \mathrm{m} 2$ & 0.037 \\
\hline
\end{tabular}

\subsubsection{Impact assessment}

The objective of the impact assessment is to quantify the impact of the activity that we are analyzing. This process gives as a result a list of environmental indicators that allow researchers, scientists or readers to analyze the impact of the process. The environmental indicators depend on the impact assessment method chosen.

The impact assessment method chosen is ReCiPe 2008 [34]. It combines two very common LCIA methods, CML, a midpoint indicator, and Eco-indicator 99, an endpoint indicator. The midpoint approach shows the basic categories of impact such as climate change or human toxicity. However, the endpoint approach unites these basic indicators of impact and displays them according to three categories of damage: to human health, to ecosystems and to the availability of resources.

$\mathrm{ReCiPe}$ combines these two methods, in the midpoint approach it provides a list of 18 impact categories, and for the endpoint one, it combines all the impacts in the three major categories of damage. The indicators of the midpoint approach of this method are: Agricultural land occupation (ALO), Climate change (GWP), Fossil depletion (FD), Freshwater ecotoxicity (FEPT), Freshwater eutrophication (FEP), Human toxicity (HTP), lonizing radiation (IRP), Marine ecotoxicity (MEPT), Marine eutrophication (MEP), Metal depletion (MD), Natural land transformation (NLT), Ozone depletion (OD), Particulate matter formation (PMF), Photochemical oxidant formation (POFP), Terrestrial acidification (TAP), Terrestrial ecotoxicity (TEPT), Urban land occupation (ULO), and Water depletion (WD).

\section{LIFE CYCLE ASSESSMENT RESULTS}

As it has been said, the Ecoinvent database considers a $19 \%$ of steel scrap (recycled steel) for the BOF process and $100 \%$ for the EAF. With these values of steel recycling associated to each process a relation about the percentage of the processes and the steel recycling ratio of the country have been done. In Table 2 we can see the steel recycling ratio and the percentage of total production of steel in Europe. 
Italy is the country which has the highest recycling ratio and, Germany together with Poland have the lowest. The impact of the BOF and EAF steel producing processes is different, cause of this, the impact in the life cycle assessment for each country is different for the same structure.

The uncertainty has been considered for each one of the processes through the matrix of pedigree. Subsequently, a Monte Carlo analysis with 5000 simulations has been done for every product. The mean values are shown in the graphs, because it is easier to compare their results.

\subsection{Midpoint approach}

The midpoint approach provides us with a high number of impact categories, but is more difficult to analyze that results, unless you are looking to reduce a specific impact category, such as the global warming or the human toxicity. In table 4 the full results of the midpoint approach are shown, including the uncertainty for Germany and Italy, the countries with the lowest and highest steel recycling ratio respectively. The differences on the coefficient of variation are due to the uncertainty associated to the steel manufacturing processes.

Table 4. Impacts caused by $28 \mathrm{~m}$ length footbridge. Mean value and coefficient of variation (cv).

\begin{tabular}{llrlrl} 
& & \multicolumn{3}{l}{ Germany } & \multicolumn{3}{l}{ Italy } \\
\cline { 3 - 6 } Acronym & Reference unit & Mean & cv (\%) & \multicolumn{1}{l}{ Mean } & cv (\%) \\
\hline ALO & m2*a & 12.28 & $27.74 \%$ & 10.15 & $23.32 \%$ \\
GWP & kg CO2-Eq & 505.21 & $27.68 \%$ & 367.12 & $20.86 \%$ \\
FD & kg oil-Eq & 107.30 & $24.27 \%$ & 89.37 & $19.94 \%$ \\
FEPT & kg 1,4-DCB-Eq & 17.31 & $33.93 \%$ & 11.34 & $25.31 \%$ \\
FEPT & kg P-Eq & 0.35 & $35.39 \%$ & 0.20 & $25.52 \%$ \\
HTP & kg 1,4-DCB-Eq & 529.24 & $32.18 \%$ & 409.39 & $26.83 \%$ \\
IRP & kg U235-Eq & 23.24 & $21.76 \%$ & 24.39 & $23.32 \%$ \\
MEPT & kg 1,4-DCB-Eq & 16.79 & $33.65 \%$ & 11.08 & $25.09 \%$ \\
MEPT & kg N-Eq & 0.09 & $28.22 \%$ & 0.07 & $20.91 \%$ \\
MD & kg Fe-Eq & 603.55 & $41.07 \%$ & 235.66 & $37.02 \%$ \\
NLT & m2 & 0.06 & $22.95 \%$ & 0.06 & $20.79 \%$ \\
ODP & kg CFC-11-Eq & 0.00 & $22.31 \%$ & 0.00 & $19.84 \%$ \\
PMFP & kg PM10-Eq & 1.72 & $31.35 \%$ & 1.13 & $22.19 \%$ \\
POFP & kg NMVOC & 1.94 & $27.80 \%$ & 1.37 & $20.08 \%$ \\
TAP & kg SO2-Eq & 1.96 & $27.05 \%$ & 1.50 & $20.58 \%$ \\
TETP & kg 1,4-DCB-Eq & 0.06 & $22.33 \%$ & 0.08 & $28.06 \%$ \\
ULO & m2*a & 6.32 & $28.19 \%$ & 4.73 & $23.02 \%$ \\
WD & m3 & 2787.10 & $34.99 \%$ & 1629.64 & $25.22 \%$ \\
\hline
\end{tabular}

The comparison between the five cities studied is carried out with the mean values of the impact because that are the representative ones. Fig. 3 shows every midpoint impact for a $28 \mathrm{~m}$ span length footbridge displayed relatively to the biggest impact for each category. 


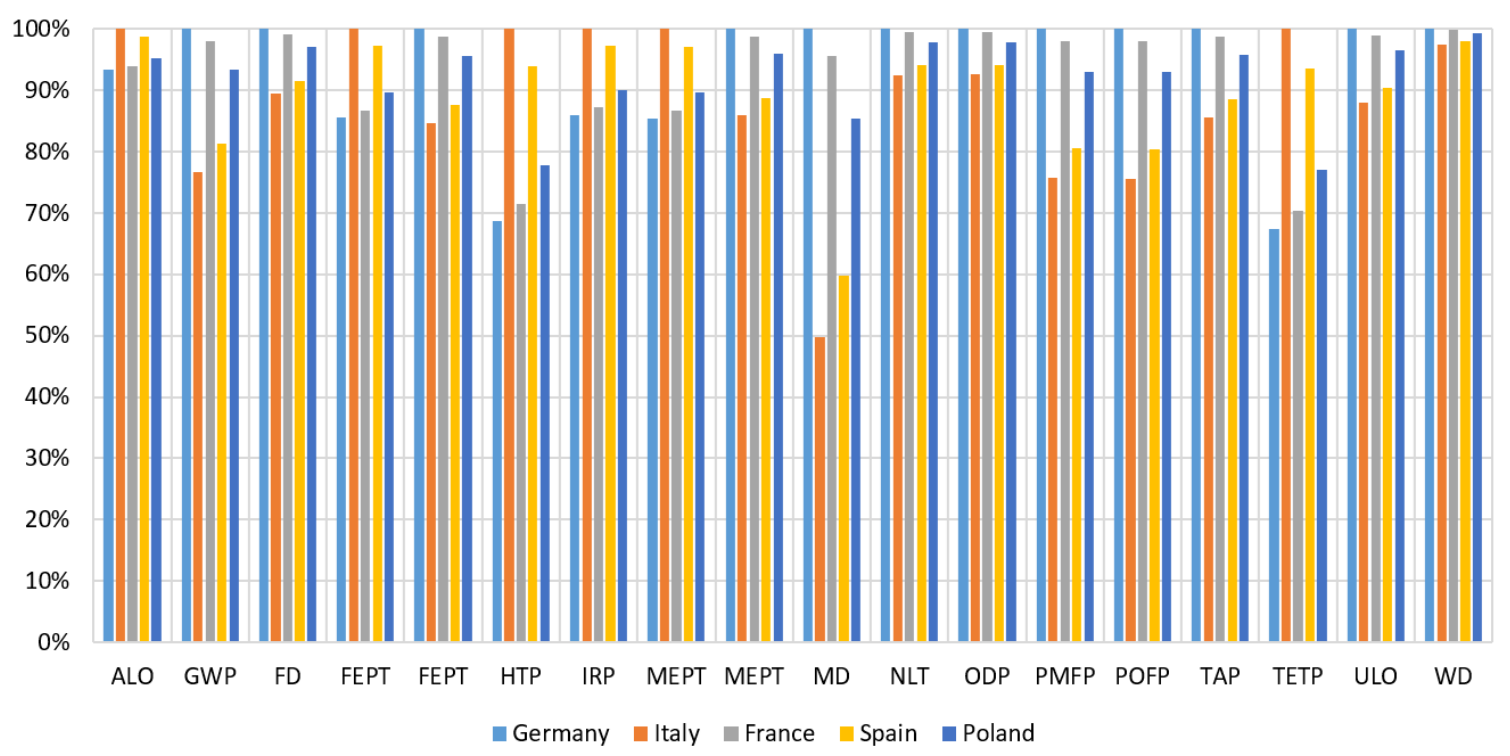

Figure 3. Midpoint impacts for $28 \mathrm{~m}$ length composite footbridge.

The impact of the amount of recycled steel is directly related with the GWP and MD, the countries that have a lower steel recycling ratio (Germany, France, Poland), compared with the countries that the process used to manufacture steel uses more recycled steel have more impact in the great majority categories. But if we focused in HTP and TETP the countries which uses more recycling steel have more impact.

\subsection{Endpoint approach}

Endpoint approach allows the possibility to compare results in an easier way. This approach gives us global results on three categories: Human Health, Ecosystems and resources. In this way, we can compare the results of the different countries among them. First the contribution of each stage of the live of the footbridge live has been studied. The importance of the manufacturing process is the most important one for every country, with fair variations, and the manufacturing process is always hanging around 93 to $95 \%$ (Fig. 4).
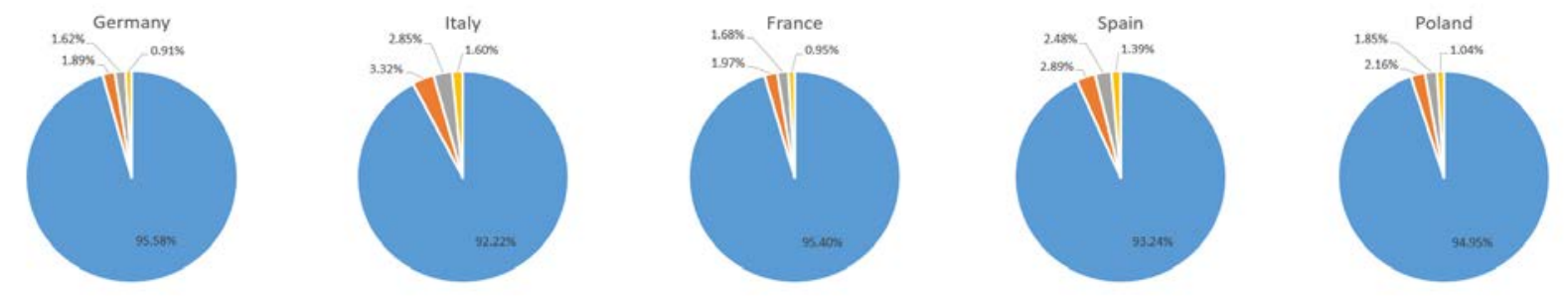

Figure 4. Contribution of each stage to total impact (\%).

The analysis of the increment of each impact categories between different countries has been done. In table 4 the relative value of the impact compared with the minimum value is shown. The highest difference is in the resources impact category value, this is because the process of BOF uses large amounts of new iron, whereas in the EAF process all the steel used in the process is recycled, according to the Ecoinvent database process. In Table 5 the values of the increment are calculated for each country and impact category. 
Table 5. Increment of each impact category compared between different countries.

\begin{tabular}{lrrrrr}
\hline Country & \%Recycled & $\begin{array}{c}\Delta \text { Ecosystem } \\
\text { quality }\end{array}$ & $\begin{array}{c}\Delta \text { Human } \\
\text { health }\end{array}$ & $\Delta$ Resources & \multicolumn{1}{c}{$\begin{array}{c}\Delta \text { Total } \\
\text { Impact }\end{array}$} \\
\hline Germany & $43.22 \%$ & $36.92 \%$ & $41.50 \%$ & $96.97 \%$ & $76.06 \%$ \\
Italy & $80.32 \%$ & $0.00 \%$ & $0.00 \%$ & $0.00 \%$ & $0.00 \%$ \\
France & $46.46 \%$ & $33.70 \%$ & $37.88 \%$ & $88.50 \%$ & $69.42 \%$ \\
Spain & $72.95 \%$ & $7.34 \%$ & $8.25 \%$ & $19.27 \%$ & $15.11 \%$ \\
Poland & $53.99 \%$ & $26.20 \%$ & $29.45 \%$ & $68.81 \%$ & $53.97 \%$ \\
\hline
\end{tabular}

The most important difference is found between Germany and Italy, and it is directly related to the percentage of steel recycled. The same steel-concrete composite footbridge has a $76.06 \%$ more environmental impact in countries on which their steel manufacturing processes use a low amount of recycled steel. This is related with the importance of the structural steel amount in that type of structures, because the other materials and construction procedures do not significantly contribute.

\section{CONCLUSIONS}

This paper has described the methodology for conducting the study of the life cycle of a previously cost optimized mixed footbridge, carried out within the framework of the subject of predictive models of optimization of concrete structures. Particularly the work consists in the realization of the life cycle analysis of this structure introducing the variable of the country of construction. It has been concluded that the steel manufacturing processes of the different countries directly influence the environmental impact of their structures, especially on steel-concrete composite footbridges where the most important material is the steel. These processes are directly related to the percentage of steel that is recycled. The structures implemented in the countries with a lower percentage of steel recycling have $76.06 \%$ more impact than the countries in which the percentage of recycling is higher and, if we focus the analysis on the use of resources it is $96.97 \%$ higher. The process that has the most contribution on the total impact of the structure is the manufacture, with a percentage between $93.24 \%$ and $95.58 \%$. This exercise allows to use a specific application for the analysis of the life cycle and to promote the transversal competencies of ethical, environmental and professional responsibility, application and practical thinking and knowledge of contemporary problems. The models for the analysis of the life cycle allow to obtain a broader vision of the impact of the structures, considering besides the cost, other aspects like the impact of our structure in the environment.

\section{ACKNOWLEDGEMENTS}

The authors acknowledge the support for the Ministry of Economy and Company and FEDER funding (Project BIA2017-85098-R).

\section{REFERENCES}

[1] E. Pellicer, C. L. Correa, and V. Yepes, "Organizational improvement through standardization of the innovation process in construction," EMV-Eng. Manag. J., vol. 24, no. 2, pp. 40-53, 2012.

[2] E. Pellicer, L. A. Sierra, and V. Yepes, "Appraisal of infrastructure sustainability by graduate students using an active-learning method," J. Clean. Prod., vol. 113, pp. 884-896, 2016.

[3] C. Torres-Machi, V. Yepes, A. Chamorro, and E. Pellicer, "Current models and practices of economic and environmental evaluation for sustainable network-level pavement management," Revista de la Construccion, vol. 13, no. 2, pp. 49-56, 2014.

[4] C. Torres-Machí, A. Carrión, V. Yepes, and E. Pellicer, "Employability of Graduate Students in Construction Management," J. Prof. Issues Eng. Educ. Pract., vol. 139, no. 2, pp. 163-170, 2013.

[5] L. A. Sierra, E. Pellicer, and V. Yepes, "Social Sustainability in the Lifecycle of Chilean Public Infrastructure," J. Constr. Eng. Manag., vol. 142, no. 5, p. 05015020, 2016. 
[6] E. Pellicer, V. Yepes, C.L. Correa, and L.F. Alarcón, "Model for Systematic Innovation in Construction Companies," J. Constr. Eng. Manag., 140, no. 4, p. B4014001, 2014.

[7] World Commission, "Report of the World Commission on Environment and Development: Our Common Future."

[8] T. Ramesh, R. Prakash, and K. K. Shukla, "Life cycle energy analysis of buildings: An overview," Energy Build., vol. 42, no. 10, pp. 1592-1600, Oct. 2010.

[9] A. Petek Gursel, E. Masanet, A. Horvath, and A. Stadel, "Life-cycle inventory analysis of concrete production: A critical review," Cem. Concr. Compos., vol. 51, pp. 38-48, Aug. 2014.

[10] A. Chen, D. M. Frangopol, and X. Ruan, "Bridge design, assessment and monitoring," Struct. Infrastruct. Eng., vol. 13, no. 4, pp. 417-417, Apr. 2017.

[11] V. Penadés-Plà, T. García-Segura, J. V. Martí, and V. Yepes, "A review of multi-criteria decisionmaking methods applied to the sustainable bridge design," Sustainability, vol. 8, no. 12, p. 1295, 2016.

[12] S. Kim and D. M. Frangopol, "Efficient multi-objective optimisation of probabilistic service life management," Struct. Infrastruct. Eng., vol. 13, no. 1, pp. 147-159, Jan. 2017.

[13] R. L. Pedro, J. Demarche, L. F. F. Miguel, and R. H. Lopez, "An efficient approach for the optimization of simply supported steel-concrete composite l-girder bridges," Adv. Eng. Softw., vol. 112, pp. 31-45, Oct. 2017.

[14] T. García-Segura and V. Yepes, "Multiobjective optimization of post-tensioned concrete box-girder road bridges considering cost, CO2 emissions, and safety," Eng. Struct., vol. 125, pp. 325-336, 2016.

[15] V. Martí, T. García-Segura, and V. Yepes, "Structural design of precast-prestressed concrete Ubeam road bridges based on embodied energy," J. Clean. Prod., vol. 120, pp. 231-240, 2016.

[16] V. Penadés-plà, T. García-Segura, and V. Yepes, "Accelerated optimization method for lowembodied energy concrete box- girder bridge design," Eng. Struct., vol. 179, pp. 556-565, 2019.

[17] T. García-Segura, V. Yepes, D.M. Frangopol, and D.Y. Yang, "Lifetime reliability-based optimization of post-tensioned box-girder bridges," Eng. Struct., vol. 145, pp. 381-391, 2017.

[18] A. Carbonell, F. González-Vidosa, and V. Yepes, "Design of reinforced concrete road vaults by heuristic optimization," Adv. Eng. Softw., vol. 42, no. 4, pp. 151-159, 2011.

[19] J. R. Martí-Vargas, F. J. Ferri, and V. Yepes, "Prediction of the transfer length of prestressing strands with neural networks," Comput. Concr., vol. 12, no. 2, pp. 187-209, 2013.

[20] T. García-Segura, V. Yepes, J. Alcalá, and E. Pérez-López, "Hybrid harmony search for sustainable design of post-tensioned concrete box-girder pedestrian bridges," Eng. Struct., vol. 92, pp. 112-122, 2015.

[21] J. V. Martí, V. Yepes, and F. González-Vidosa, "Memetic algorithm approach to designing precast-prestressed concrete road bridges with steel fiber reinforcement," J. Struct. Eng., vol. 141, no. 2, p. 04014114, 2015.

[22] V. Yepes, C. Torres-Machi, A. Chamorro, and E. Pellicer, "Optimal pavement maintenance programs based on a hybrid Greedy Randomized Adaptive Search Procedure Algorithm," J. Civ. Eng. Manag., vol. 22, no. 4, pp. 540-550, 2016.

[23] V. Penadés-Plà, T. García-Segura, and V. Yepes, "An optimization-LCA of a prestressed concrete precast bridge," Sustainability, vol. 10, no. 3, p. 685, 2018.

[24] T. García-Segura, V. Penadés-Plà, and V. Yepes, "Sustainable bridge design by metamodelassisted multi-objective optimization and decision-making under uncertainty," J. Clean. Prod., vol. 202, pp. 904-915, 2019.

[25] D. M. Frangopol, Y. Dong, and S. Sabatino, "Bridge life-cycle performance and cost: analysis, prediction, optimisation and decision-making," Struct. Infrastruct. Eng., vol. 13, no. 10, pp. 12391257, Oct. 2017.

[26] J. J. Pons, V. Penadés-Plà, V. Yepes, and J. V. Martí, "Life cycle assessment of earth-retaining walls: An environmental comparison," J. Clean. Prod., vol. 192, pp. 411-420, 2018. 
[27] P. Zastrow, F. Molina-Moreno, T. García-Segura, J. V. Martí, and V. Yepes, "Life cycle assessment of cost-optimized buttress earth-retaining walls: A parametric study," J. Clean. Prod., vol. 140, pp. 1037-1048, 2017.

[28] V. Penadés-Plà, J. V. Martí, T. García-Segura, and V. Yepes, "Life-cycle assessment: A comparison between two optimal post-tensioned concrete box-girder road bridges," Sustainability, vol. 9, no. 10, p. UNSP 1864, 2017.

[29] D. K. Panesar, K. E. Seto, and C. J. Churchill, "Impact of the selection of functional unit on the life cycle assessment of green concrete," Int. J. Life Cycle Assess., vol. 22, no. 12, pp. 1969-1986, Dec. 2017.

[30] B. Pang, P. Yang, Y. Wang, A. Kendall, H. Xie, and Y. Zhang, "Life cycle environmental impact assessment of a bridge with different strengthening schemes," Int. J. Life Cycle Assess., vol. 20, no. 9, pp. 1300-1311, 2015.

[31] R. Frischknecht et al., "The ecoinvent database: Overview and methodological framework," Int. J. Life Cycle Assess., vol. 10, no. 1, pp. 3-9, 2005.

[32] A. Ciroth, S. Muller, B. Weidema, and P. Lesage, "Empirically based uncertainty factors for the pedigree matrix in ecoinvent," Int. J. Life Cycle Assess., vol. 21, no. 9, pp. 1338-1348, 2016.

[33] World Steel Association, "Steel Statistical Yearbook 2018," World Steel Assoc., 2018.

[34] M. Goedkoop, R. Heijungs, M. Huijbregts, A. De Schryver, J. Struijs, and R. Van Zelm, "ReCiPe 2008," Rep. I Characterisation, no. January, pp. 1-44, 2009. 